\title{
A protocol for the simultaneous identification of chitin-containing particles and their associated bacteria
}

\author{
Florencia Biancalana ${ }^{\mathrm{a}, *}$, Germán A. Kopprio ${ }^{\mathrm{a}, \mathrm{b}}$, Rubén J. Lara ${ }^{\mathrm{a}}$, Cecilia Alonso ${ }^{\mathrm{c}}$ \\ a Instituto Argentino de Oceanografí, Consejo Nacional de Investigaciones Científicas y Técnicas and Universidad Nacional del Sur, Florida 4750, \\ B8000FWB Bahía Blanca, Argentina \\ ${ }^{\mathrm{b}}$ Leibniz Center for Tropical Marine Ecology (ZMT), Fahrenheitstr. 6, 28359 Bremen, Germany \\ ${ }^{\mathrm{c}}$ Microbial Ecology of Aquatic Transitional Systems Research Group, Centro Universitario Región Este, Universidad de la República, Ruta nacional N 9,2700 \\ Rocha, Uruguay
}

\section{A R T I C L E I N F O}

\section{Article history:}

Received 23 December 2016

Received in revised form 7 May 2017

Accepted 12 May 2017

\section{Keywords:}

Chitin

WGA

Bacteria

CARD-FISH

Sestonic aggregates

\begin{abstract}
A B S T R A C T
Chitin is the second most abundant polymer on Earth, playing a crucial role in the biogeochemical cycles. A core issue for studying its processing in aquatic systems is the identification and enumeration of chitin-containing particles and organisms, ideally in a manner that can be directly linked to bulk chitin quantification. The aim of this study was the development of such a technique. We successfully combined the methodology of bulk chitin determination using wheat germ agglutinin (FITCWGA) for staining chitin-containing particles and organisms along with CARD-FISH staining of either chitin-containing eukaryotic cells or bacteria associated with them. Environmental chitin staining was successfully applied to natural water samples. Fungal hyphae, diatoms, and dinoflagellates, sestonic aggregates and chitin-containing structures derived from metazoa were observed. Also, hybridized bacteria attached to chitinaceous debris were clearly visualized. Finally, as proof of principle, cultured yeast cells were simultaneously-targeted by FITC-WGA and the EUK516 probe without exhibiting any interference between both stains. The presented approach appears as a powerful tool to evaluate the contribution of different size classes and organisms to chitin production and consumption, opening the possibility for application of single-cell approaches targeting the ecophysiology of chitin transformations in aquatic systems.
\end{abstract}

(c) 2017 Elsevier GmbH. All rights reserved.

\section{Introduction}

Chitin is a natural polymer widely distributed in nature, which is mostly found in fungi and invertebrates [22]. In marine systems, euphausiids and copepods are the main chitin producers $[26,38]$, since it is a component of their exoskeletons, exuviae and faecal pellets $[28,60]$. In addition, there are also some diatom genera, such as Thalassiosira and Skeletonema, which produce chitin as a significant constituent of their biomass [54]. The polymer is also present in the cyst walls of some ciliates, flagellates and amoebae, in the lorica walls of certain ciliates, and in the cell walls of fungi [22,59].

Chitin plays a crucial role in the carbon and nitrogen biogeochemical cycles [55]. A continual rain of chitin is deposited on the ocean floor that is formed by dynamic processes such as molting cuticles and the senescence of planktonic organisms. This chitin

\footnotetext{
* Corresponding author. Fax: +54 2914861112.

E-mail address: biancaf@criba.edu.ar (F. Biancalana).
}

supply forms part of the particulate aggregates known as "marine snow" [3]. These aggregates harbour rich detrital communities of eukaryotic and prokaryotic organisms, which represent an important site for the biological processes of production, decomposition and nutrient recycling in the water column [2].

Despite the continuous deposition of this highly insoluble polymer, low quantities of chitin are found in ocean sediments [43], a phenomenon which mainly results from the activity of chitindegrading bacteria [7,22]. In addition, certain fungi and diatoms are also capable of chitin hydrolysis [41,56,58]. Although it has been estimated that only a very low fraction of bacterial communities is chitinolytic, a much higher proportion is able to utilize chitin hydrolysates [47]. Despite the long-standing recognition of the specific interaction of certain members of the aquatic bacterial communities with chitin particles (i.e. Vibrio cholera [44]), the production of extracellular chitinases has been detected in other bacterial species [29]. In fact, it has recently been proposed that bacterial community composition might actually play a significant role in chitin degradation rates modulated by environmental 
factors such as temperature and abundance of zooplankton and phytoplankton [8]. Therefore, the identification and quantification of chitin-containing particles, and their associated bacteria, is necessary for a deeper understanding of chitin processing in aquatic environments.

Typically, chitin-containing cells have been enumerated by employing the fluorescence brightener Calcofluor [15,24,25,46], which interacts with $\beta$-linked D-glucopyranose polysaccharides, including chitin. However, it preferentially stains cellulose, which is another polysaccharide frequently found in the particles and organisms of aquatic systems [31]. More recently, to overcome this specificity issue, and to be able to combine chitin staining using fluorescent in situ hybridization together with oligonucleotide probes (FISH), Würzbacher and Grossart [59] proposed the use of the fluorescently labeled chitin-binding domain (CBD) to detect and identify aquatic fungi. In addition, fungi have also been quantified in aquatic samples using CARD-FISH, without specific chitin counter staining [27].

However, none of these techniques provides a direct link for the identification and quantification of chitin-containing particles with bulk estimates of chitin concentration. A simple method for bulk chitin determination in water and sediment samples relies on the staining of chitin-containing particles with fluorescein succinylated wheat-germ agglutinin (FITC-WGA) [34]. WGA is a sugar-binding protein that has a high affinity for $\mathrm{N}$ acetylglucosamine residues [4], which is the major component of chitin. WGA has been shown to bind specifically to this polymer, even when samples contain high concentrations of cellulose, clay and bacteria [34], and it is more specific than Calcofluor for the determination of chitin [32].

Despite the fact that WGA can also react weakly with $\mathrm{N}$-acetylneuraminic acid residues [14,21], which are found in fungi and other biological samples [5,10], Monsigny et al. [33] reported that, in contrast to the native lectin, succinylated-WGA did not recognize $\mathrm{N}$-acetyl-neuraminic acid residues, but still maintained the same affinity for $\mathrm{N}$-acetylglucosamine residues as the native lectin. Nevertheless, due to its affinity for $\mathrm{N}$-acetylglucosamine residues, WGA could also potentially stain the thick peptidoglycan layer of Gram-positive bacteria [50,57].

In histological studies, this lectin has been widely used to localize chitin in the cell walls of fungi $[19,32,52]$, as well as in molluscs and insects [40]. It is also employed to enumerate diatoms and crustacean eggs containing chitin [17,42].

Although FITC-WGA staining of chitin to date has not been used together with CARD-FISH, Bennke et al. [9] proposed a technique combining CARD-FISH and staining with (other) fluorescent lectins, demonstrating the potential of such combined methods to identify bacteria associated with extracellular polymeric substances.

In this study, a novel combined protocol was developed for FITC-WGA staining of chitin-containing particles and organisms together with CARD-FISH staining of chitin-containing eukaryotic cells and/or their associated bacterial cells.

\section{Materials and methods}

A set of samples from Bahia Blanca Estuary (BBE, Argentina) was used for developing the protocol. Water was pre-filtered with a $20 \mu \mathrm{m}$ net, in order to obtain the size fraction $\leq 20 \mu \mathrm{m}$ that previous studies had shown contains the major bulk fraction of chitin in certain marine environments, including BBE [11,22,30].

Pre-filtered samples were fixed with freshly prepared buffered paraformaldehyde solution (PFA) at a final concentration of $1 \%$ at $4{ }^{\circ} \mathrm{C}$ for $24 \mathrm{~h}$. Portions of $10 \mathrm{~mL}$ were then filtered through $25 \mathrm{~mm}$ diameter type GTTP polycarbonate filters with a $0.2 \mu \mathrm{m}$ pore size
(GAMAFIL). The filters were rinsed twice with sterile phosphate buffered saline (PBS) and stored at $-20^{\circ} \mathrm{C}$ until further analysis.

In order to provide a known positive control for the technique, a culture of commercial baker's yeast (Saccharomyces cerevisiae) was established in sterile water amended with saccharose. After visible cell growth, and within $24 \mathrm{~h}$ of starting the cultivation, the yeast cells were fixed with PFA at a final concentration of $1 \%$ for $1 \mathrm{~h}$ at room temperature.

Once established, the protocol was also performed on samples from the Atlantic Uruguayan coast, in order to check its applicability to a different system, as well as samples from BBE that had not been pre-filtered previously through $20 \mu \mathrm{m}$ mesh. Samples from the Atlantic Uruguayan coast were also fixed with 1\% PFA, and filtered through $0.2 \mu \mathrm{m}$ pore size $47 \mathrm{~mm}$ diameter polycarbonate filters (Millipore). Whole water samples from BBE were fixed and filtered as described above.

The new protocol was set up by combining the methodology of chitin determination using wheat-germ agglutinin (FITC-WGA) [34] and the protocol for bacterial identification using in situ hybridization with horseradish peroxidase (HRP)-labeled probes linked to catalyzed reporter deposition (CARD-FISH) [39]. The reagent solution for FITC-WGA was prepared by adding $8 \mu \mathrm{L}$ FITC-WGA (Vector Laboratories) to $2 \mathrm{~mL}$ phosphate buffer ( $1 \mathrm{M}$ $\mathrm{Na}_{2} \mathrm{HPO}_{4}, \mathrm{pH}$ 9.25). For CARD-FISH, the following HRP-labeled probes (biomers.net, Ulm, Germany) were used: EUB338 I-III (most Bacteria) [16] for hybridization of natural water samples, and EUK516 (most Eukarya) [6] for staining the yeast culture. Between 1 and $3 \mu \mathrm{L}$ of a $50 \mathrm{ng} \mu \mathrm{L}^{-1}$ stock solution of each HRP probe were employed for every $100 \mu \mathrm{L}$ of hybridization buffer [0.9 M NaCl, $20 \mathrm{mM}$ Tris- $\mathrm{HCl}, \mathrm{pH}$ 8.0, 0.02\% SDS, 1\% blocking reagent (Roche), $55 \%$ formamide]. After hybridization, unbound probe was removed by incubating the samples in washing buffer $[20 \mathrm{mM}$ Tris- $\mathrm{HCl}$, pH 8.0, $5 \mathrm{mM}$ EDTA (pH 8.0), 0.003 M NaCl, 0.01\% SDS]. Samples were then incubated in $1 \mathrm{X}$ PBS $[0.14 \mathrm{M} \mathrm{NaCl}, 2.7 \mathrm{mM} \mathrm{KCl}$, $10 \mathrm{mM} \mathrm{Na}_{2} \mathrm{HPO}_{4}, 1.8 \mathrm{mM} \mathrm{KH}_{2} \mathrm{PO}_{4}$ ]. Tyramide conjugated with redfluorescing Alexa 594 (molecular probes) was used to reveal the hybridizations in order to distinguish them from green-fluorescing WGA chitin staining. Following washing, the samples were incubated with tyramide-containing amplification buffer [ $2 \mathrm{M} \mathrm{NaCl}$, $10 \%$ dextran sulfate, $0.1 \%$ blocking reagent (Roche), $1 \mathrm{X}$ PBS, $0.15 \%$ $\mathrm{H}_{2} \mathrm{O}_{2}, 1 \mu \mathrm{g} \mu \mathrm{L}^{-1}$ tyramide]. A final wash in $1 \mathrm{X}$ PBS was carried out for another $15 \mathrm{~min}$. CARD-FISH + WGA-stained preparations were counterstained with DAPI at a final concentration of $1 \mu \mathrm{g} \mathrm{mL}^{-1}$, in order to check for possible artifacts in their respective signals.

Microscopic images were captured by a Leica DMLS2 fluorescence microscope with a Nikon DXM1200F camera, as well as an Olympus IX81 with a CCD Model DP71 camera, and a confocal Olympus BX61 laser microscope. Microscopic images were processed with the J Image program [18].

Different tests were carried out in order to establish the final protocol. In particular, the following were tested:

i) Whether common cell permeabilization protocols for CARDFISH interfered with FITC-WGA staining. Assayed permeabilization protocols were: a) treatment with $10 \mathrm{mg} \mathrm{mL}^{-1}$ lysozyme (AppliChem, Darmstadt, Germany) for $1 \mathrm{~h}$ at $37^{\circ} \mathrm{C}$ for natural water samples, or b) treatment with $1 \mathrm{mg} \mathrm{mL}^{-1}$ proteinase $\mathrm{K}$ (Ambion, USA) for $1 \mathrm{~h}$ at $37^{\circ} \mathrm{C}$ for natural samples, and for one and four hours at $37^{\circ} \mathrm{C}$ for the yeast culture.

ii) Different temperatures and times for FITC-WGA staining and washing. Staining was performed on natural samples at: a) $35^{\circ} \mathrm{C}$ for two hours, b) $35^{\circ} \mathrm{C}$ for three hours, and c) overnight at $30^{\circ} \mathrm{C}$. Washing after staining was undertaken in $1 \mathrm{X}$ PBS at room temperature for either 15 or $30 \mathrm{~min}$ in the dark. The assayed temperatures and times for staining were chosen taking into account the protocol for chitin determination [34] and CARD- 

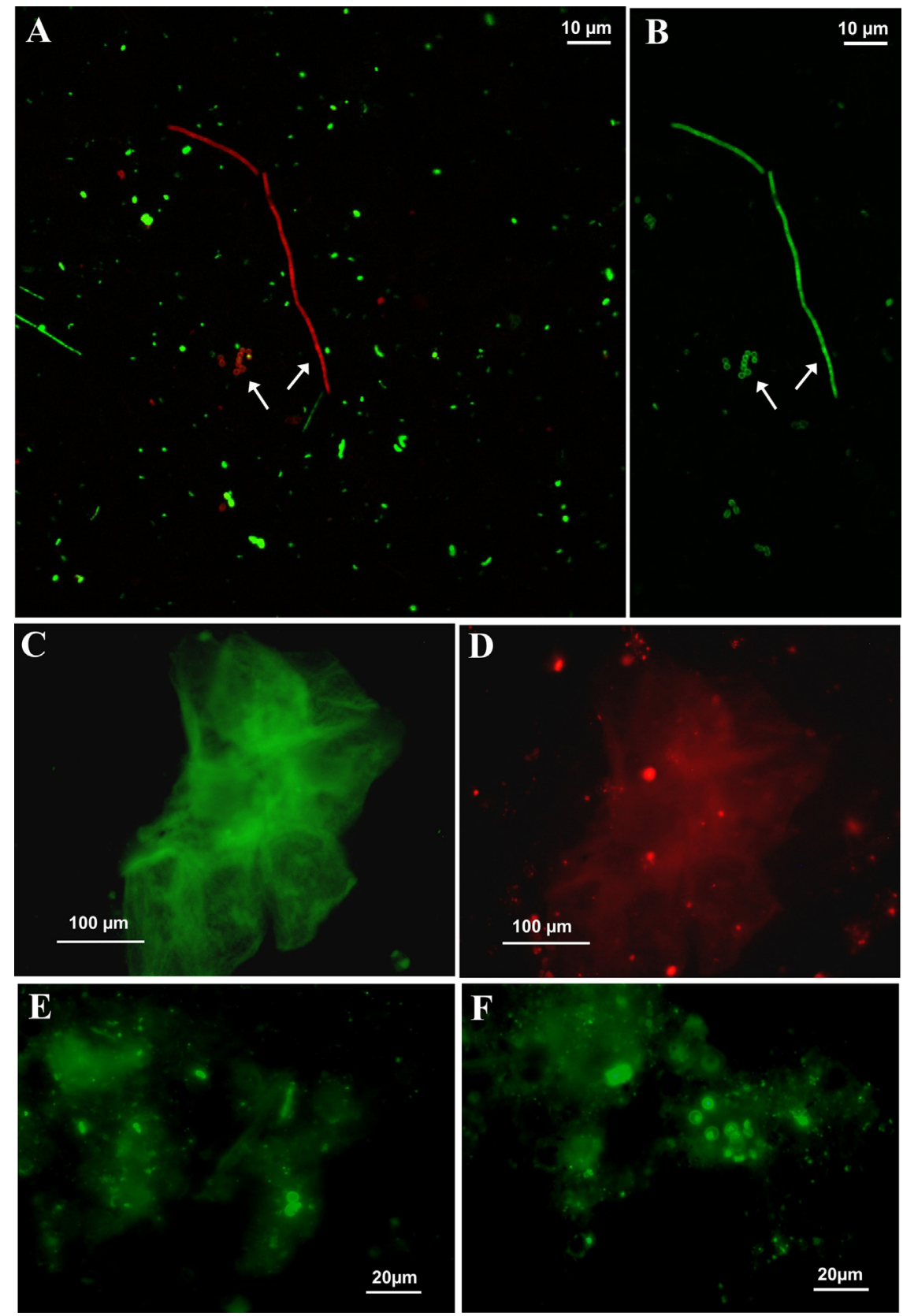

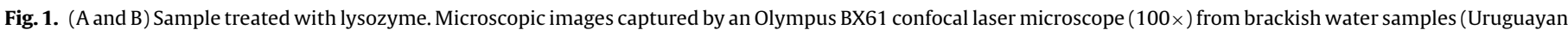

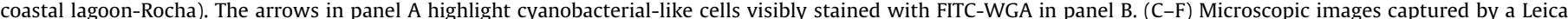

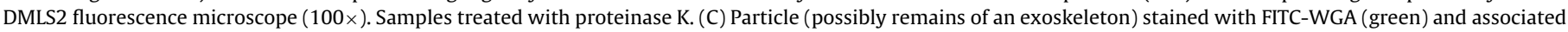

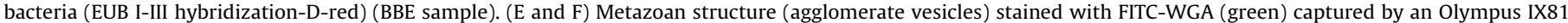

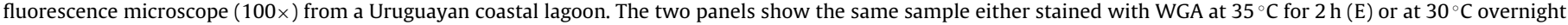
(F). (For interpretation of the references to color in this figure legend, the reader is referred to the web version of this article.)

FISH [28]. A temperature of $30^{\circ} \mathrm{C}$ overnight and, at most, $33^{\circ} \mathrm{C}$ for $4 \mathrm{~h}$ were optimal for the determination of chitin in aquatic samples [34], whereas standard CARD-FISH protocols were run at $35^{\circ} \mathrm{C}$. On this basis, an increase in temperature and a reduction in the time were tested for staining with WGA, discarding the combinations $30^{\circ} \mathrm{C}$ for two hours and $35^{\circ} \mathrm{C}$ overnight.

iii) Whether hybridization with HRP-probes interfered with FITCWGA staining of the same sample and vice versa. To check whether hybridization with HRP-probes interfered with FITCWGA staining, hybridization was performed before and after FITC-WGA staining. This assay was carried out on natural samples. iv) Whether hybridization and FITC-WGA staining could be simultaneously carried out. The yeast culture was used to check if hybridization and FITC-WGA staining could be simultaneously performed on the same cell, and the order of the procedures was also tested.

Furthermore, the capability of visualization and enumeration of FITC-WGA stained particles with flow cytometry was tested for both the yeast culture and the natural samples. For this purpose, fixed liquid samples of either yeast culture or natural planktonic communities were stained with FITC-WGA at $35^{\circ} \mathrm{C}$ for two hours. After staining, samples were centrifuged at $12,000 \mathrm{rpm}$ and $15^{\circ} \mathrm{C}$ for $5 \mathrm{~min}$, and washed twice with sterile $1 \mathrm{X}$ PBS. After the sec- 

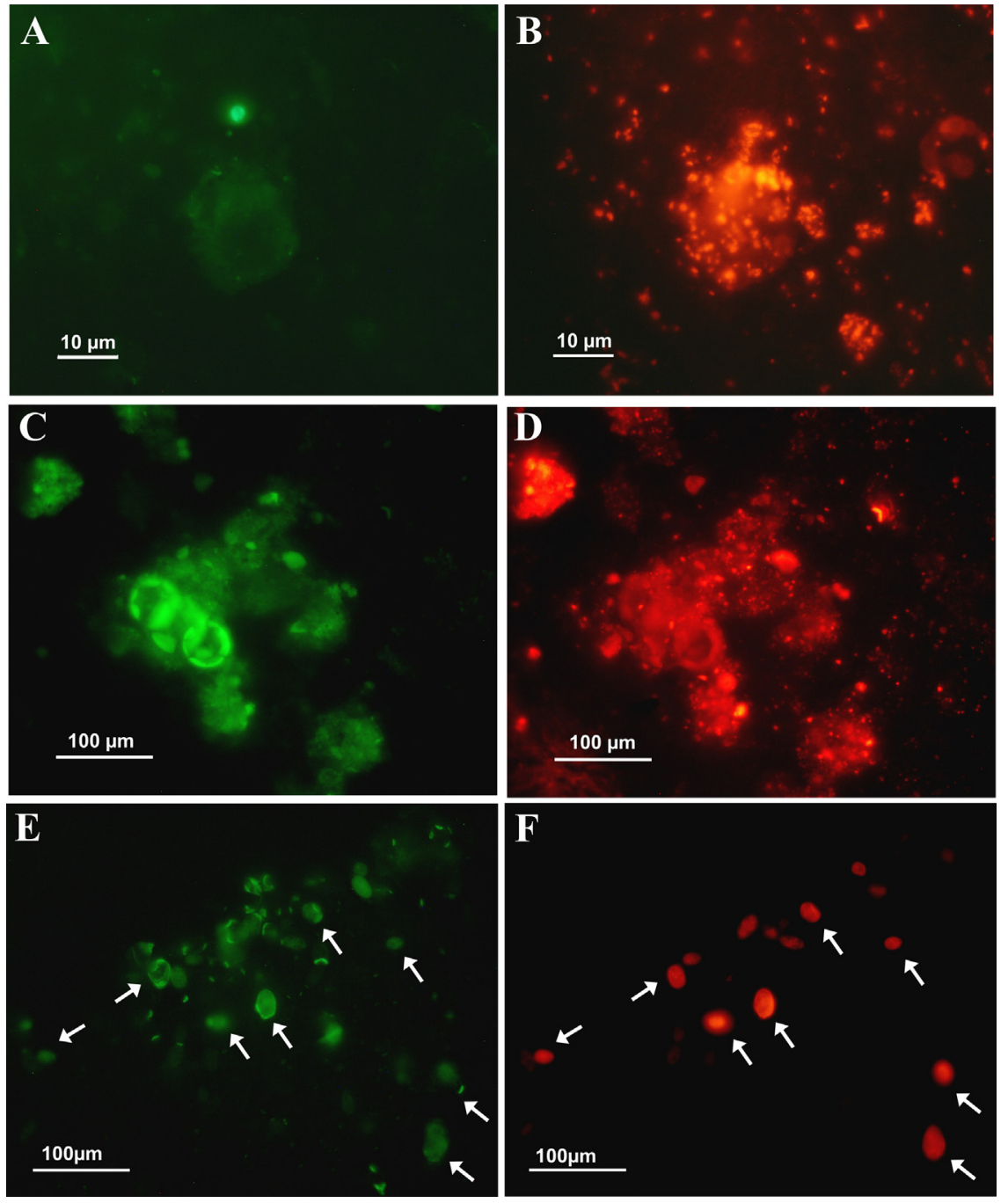

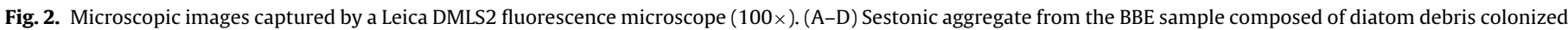

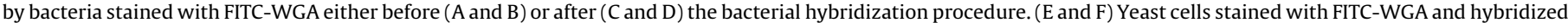
with EUK 516

ond wash, the sample was re-suspended with sterile Milli- $\mathrm{Q}^{\circledR}$ (MQ) water and analyzed in a flow cytometer (MicroA50, Apogee Flow Systems) according to its green fluorescence and side scatter.

\section{Results and discussion}

The CARD-FISH lysozyme permeabilization protocol did not interfere with FITC-WGA staining (Fig. 1A and B). In fact, samples treated with lysozyme showed more permanent and less photosensitive staining than those not previously treated. Furthermore, permeabilization with proteinase $\mathrm{K}$ did not interfere with WGA staining either (Fig. 1C and D).

An improvement in FITC-WGA staining after the lysozyme treatment agreed with the observation that some lysozymes (i.e. the egg-white lysozyme used here) may also hydrolyze chitin [35], although at a lower level than chitinases [51]. On the other hand, chitin is generally associated with proteins or with other polysaccharides in nature [12,20,37], and proteinase $\mathrm{K}$ treatment might have improved the accessibility of WGA to chitin in particles and cell walls. Moreover, the use of proteinase $\mathrm{K}$ to remove protein partially from fungal spore walls has been shown to result in a substantial improvement in the percentage of stained spores $[45,48]$. Thus, treatment with any of the enzymes typically used in the
CARD-FISH permeabilization step is in fact advantageous for staining chitin-containing particles.

Regarding the FITC-WGA staining temperature and time, the optimal settings were either two hours at $35^{\circ} \mathrm{C}$ or overnight at $30^{\circ} \mathrm{C}$ (Fig. 1E and F). Washing samples with $1 \mathrm{X}$ PBS at room temperature was equally suitable for 15 or 30 min when little chitinaceous material was found in the sample, while washing for $30 \mathrm{~min}$ was preferable when the samples were charged with chitin-containing particles, which helped to ensure low-level background.

Hybridization with HRP-labeled probes did not interfere with FITC-WGA staining, and vice versa. FITC-WGA stained particles were perfectly visible after hybridization (Fig. 2A and B) and hybridized bacteria were equally visible after FITC-WGA staining (Fig. 2C and D). Thus, FITC-WGA staining could be applied before or after hybridization without any noticeable change in the quality of the images obtained.

Bennke et al. [9] suggested that fluorescent lectin binding analysis (FLBA) was better performed after the hybridization procedure because the lectin-specific signals were stronger compared to labeling carried out before CARD-FISH. However, in our final protocol, it was recommended to perform FITC-WGA staining prior to hybridization in order to reduce the time of total processing, allowing hybridization to proceed overnight. In addition, re-staining with 
Table 1

Detailed protocol for the FITC-WGA and CARD-FISH combination.

\begin{tabular}{|c|c|c|}
\hline Procedure & Step & Description \\
\hline Preparation of samples & $\begin{array}{l}1 \\
2\end{array}$ & $\begin{array}{l}\text { Embed filters in } 0.1 \% \text { agarose } \\
\text { Air dry the filters }\end{array}$ \\
\hline \multicolumn{3}{|c|}{ Permeabilization alternatives: } \\
\hline \multirow[t]{2}{*}{ A-with lysozyme } & 3 & Incubate filters in lysozyme solution $\left(10 \mathrm{mg} \mathrm{mL}^{-1}\right)\left(37^{\circ} \mathrm{C}, 1 \mathrm{~h}\right)$ \\
\hline & 4 & Wash with MQ water several times (room temperature-RT) \\
\hline \multirow[t]{2}{*}{$\mathrm{B}$-with proteinase $\mathrm{K}$} & 3 & Incubate filters in proteinase $\mathrm{K}$ solution $\left(1 \mathrm{mg} \mathrm{mL}^{-1}\right)\left(37^{\circ} \mathrm{C}, 1 \mathrm{~h}\right.$ for natural samples, $4 \mathrm{~h}$ for yeast culture $)$ \\
\hline & 4 & Wash with MQ water several times ( 1 min at RT) \\
\hline \multirow{3}{*}{$\begin{array}{l}\text { Inactivation of } \\
\text { peroxidases }\end{array}$} & 5 & Incubate filters in $0.01 \mathrm{M} \mathrm{HCl}(1 \mathrm{~mL} /$ filter $)$ (20 min at RT) \\
\hline & 6 & Wash filters with MQ water several times (RT) \\
\hline & 7 & Air dry the filters \\
\hline Staining with & 8 & Incubate filters with a drop of $10-30 \mu \mathrm{L}$ FITC-WGA at $30^{\circ} \mathrm{C}$ overnight or at $35^{\circ} \mathrm{C}$ for $2 \mathrm{~h}$ \\
\hline \multirow[t]{3}{*}{ FITC-WGA } & 9 & Incubate filters with $1 \mathrm{X}$ PBS for 15-30 min at room temperature (RT) \\
\hline & 10 & Wash filters with MQ water three times ( 1 min each at RT) \\
\hline & 11 & Air dry the filters \\
\hline \multirow[t]{4}{*}{ Hybridization } & 12 & Mix hybridization buffer and probe working solution and add to filter sections \\
\hline & 13 & Incubate filters for at least $2 \mathrm{~h}$ or overnight at $35^{\circ} \mathrm{C}$ \\
\hline & 14 & Wash filters in pre-warmed washing buffer $\left(37^{\circ} \mathrm{C}, 15 \mathrm{~min}\right.$, $)$ \\
\hline & 15 & Incubate filters in $1 \mathrm{X}$ PBS for $15 \mathrm{~min}$ at $\mathrm{RT}$ \\
\hline \multirow{4}{*}{$\begin{array}{l}\text { Amplification and } \\
\text { washing }\end{array}$} & 16 & Incubate filters in substrate mix with Alexa 594-conjugated tyramide for $15 \mathrm{~min}$ at $37^{\circ} \mathrm{C}$ in the dark \\
\hline & 17 & Incubate filters in $1 \mathrm{X} \mathrm{PBS}$ for $15 \mathrm{~min}$ at $37^{\circ} \mathrm{C}$ in the dark \\
\hline & 18 & Wash filters with MQ several times \\
\hline & 19 & Air dry the filters in the dark \\
\hline \multirow[t]{2}{*}{ Staining with DAPI } & 20 & Stain with DAPI ( $1 \mu \mathrm{g} \mathrm{mL} \mathrm{m}^{-1}$ solution) for $3 \mathrm{~min}$ in the dark \\
\hline & 21 & Rinse with MQ water, air dry and mount the filter on a microscope slide \\
\hline
\end{tabular}

FITC-WGA was also possible prior to DAPI staining, if needed, without resulting in an increased intensity green background (Fig. 2C).

Finally, it was also possible to combine chitin staining and phylogenetic staining of the same organism (baker's yeast); therefore, opening up the possibility of further identification of chitincontaining cells (Fig. 2E and F).

A detailed protocol of all the steps for sample processing of simultaneous FITC-WGA and CARD-FISH is provided in Table 1

Environmental chitin staining was successful for natural water samples, and there was no interference with the observation of different structures and organisms even in samples exhibiting high background fluorescence (Fig. 3). Background fluorescence has been described for some lectins after performing fluorescent lectin staining on agarose-embedded samples [9]. Although in the current study this was not specifically tested for, there were no empirical clues that this could be the case for this lectin. In most of the samples, the background was very clean and dark (Fig. 3C, D and F), and even when samples showed a brighter background, the target signals (i.e. found in recognizable organisms) were still much brighter than the background (Fig. 3A, B and E). Thus, it was found that interference with agarose embedding was not a problem for this lectin, at least in the set of samples used.

Individual chitin-containing organisms, such as fungal hyphae, as well as diatoms and dinoflagellates, were identified in the samples (Fig. 3A-C). In addition, chitin-containing structures derived from metazoans were visible (Figs. 1E-F, 3D).

Unexpectedly, it was possible to observe WGA staining of the peripheries of cells that seemed to be Cyanobacteria (Fig. 1A and $\mathrm{B}$ ). Although chitin is known as a widespread polymer that accounts for an important biomass fraction of different organisms $[17,22,53,54,59]$, these result highlighted how direct visualization of natural samples can certainly provide new insights into its distribution among planktonic cells. Nevertheless, the results should be carefully interpreted with regard to possible cross-reactivity. As mentioned in the introduction, the use of the derivative succinylated-WGA improves specificity to sialic acid residues found in fungi and other organisms [14,21], but the affinity for the exposed peptidoglycan layer of Gram-positive bacteria is still an option, which is particularly relevant in freshwaters where these organisms can constitute a high fraction of the bacterial community [49].

In addition to individual organisms, it was possible to stain sestonic aggregates composed of diatoms, bacteria, fungal hyphae and other chitin-containing cells (Figs. 2A-D, 3C, E and F). Although in this set of samples the exclusively chitin-made debris was not extensively colonized, it was still possible to visualize hybridized bacteria associated with them (Fig. 1C and D). In contrast, presumed senescent chitin-containing cells were heavily colonized (Fig. 2A-D).

Finally, it was possible to detect FITC-WGA stained cells using flow cytometry, which were seen to form distinctive cytometric populations (data not shown), therefore, providing an opportunity for counting and sorting different chitin-containing particles in the pico- and nanoplankton size range.

The results of this study indicated that the new protocol simultaneously using FITC-WGA and CARD-FISH had great potential for the identification and quantification of organisms producing and/or degrading chitin in aquatic systems, both under fluorescence microscopy and, potentially, by flow cytometry. In combination with bulk measurements of chitin obtained by FITC-WGA staining [34], it therefore represents a powerful tool for evaluating the contribution of different size classes and organisms to chitin production and consumption.

Moreover, the possibility of simultaneous identification of chitin-containing organisms and their associated bacteria represented an excellent complementary approach to recent metagenomic-based studies analyzing the diversity of chitinolytic members of microbial communities [8]. Direct microscopic visualization of these associations can provide further insights into the key players involved in chitin processing, as has been successfully demonstrated for other relevant biogeochemical processes, such as anaerobic methane oxidation [13].

Microscopy can also reveal the extent of the specificity of associations between chitin producers and consumers, as already shown for the phytoplankton-flavobacterial associations based on cellsurface molecule interactions [9]. Furthermore, in combination with isotopic tracer-based techniques, it can be used to estimate 

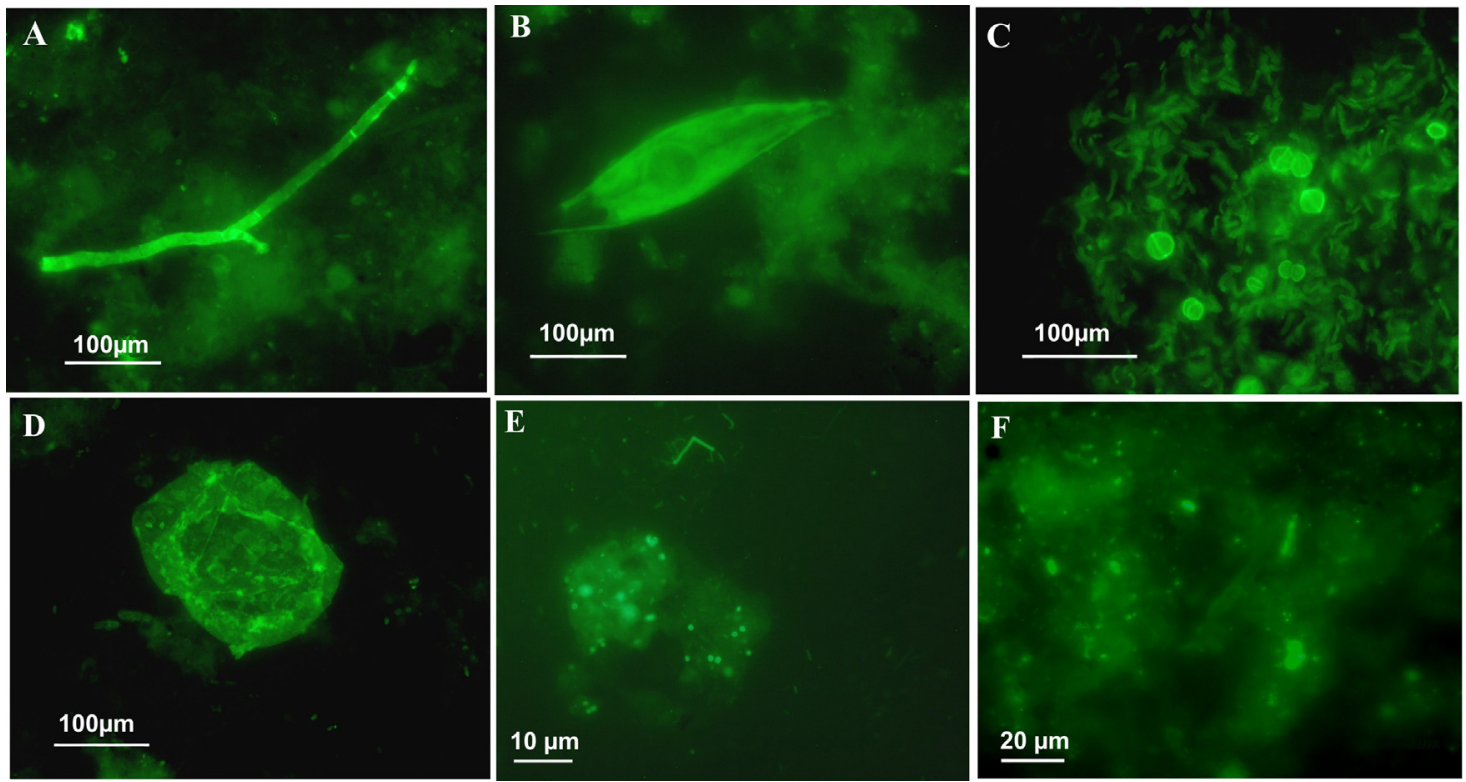

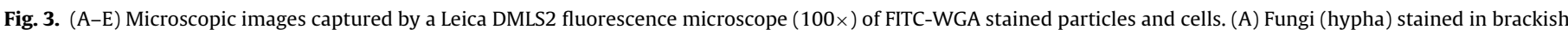

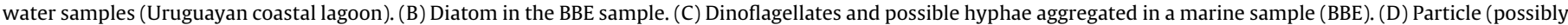

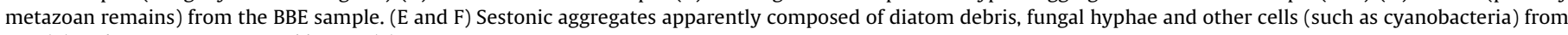
BBE (E) and a Uruguayan coastal lagoon (F).

the rates of chitin synthesis and hydrolysis at the single-cell level, shedding light on the eukaryotic-prokaryotic interactions involved [1], and even leading to a quantitative assessment of the contribution of target taxa [36]. Altogether, the new protocol represents a further contribution to the understanding of the tight coupling between chitin production and consumption, as shown by the rapid turnover of this abundant polymer in aquatic systems [23].

\section{Acknowledgements}

This work was supported by the Agencia Nacional de Promoción Científica y Tecnológica (PICT-2012-2796.), cooperation project MOV-CO-2014-1-102552 funded by the bi-national program Consejo Nacional de Investigaciones Científicas y Técnicas-Agencia Nacional de Investigación e Innovación (CONICET-ANII, ArgentinaUruguay), and by a Científicas y Técnicas-Agencia Nacional de Investigación e Innovación (CONICET) grant. We are grateful to Dr. Paola Scavone and Lic. Victoria Iribarnegaray for their help with the utilization of the confocal laser microscope at the Instituto de Investigaciones Biológicas Clemente Estable (Montevideo, Uruguay). We also thank Dr. Anabela A. Berasategui for her support and help during the sampling period. Three anonymous reviewers are acknowledged for their insightful and constructive comments that very much helped to improve the quality of the original manuscript.

\section{References}

[1] Alonso, C., Musat, N., Adam, B., Kuypers, M., Amann, R. (2012) HISH-SIMS analysis of bacterial uptake of algal-derived carbon in the Río de la Plata estuary. Syst. Appl. Microbiol. 35, 541-548.

[2] Alldredge, A., Silver, M.W. (1988) Characteristic, dynamics and significance of marine snow. Prog. Oceanog. 20, 41-82

[3] Alldredge, A.L., Gotschalk, C.C. (1990) The relative contribution of marine snow of different origins to biological processes in coastal waters. Cont. Shelf Res. 10, 41-58.

[4] Allen, A.K., Neuberger, A., Sharon, N. (1973) The purification, composition and specificity of wheat-germ agglutinin. Biochem. J. 131, 155-162.

[5] Alviano, C.S., Travassos, L.R., Schauer, R. (1999) Sialic acids in fungi: a minireview. Glycoconj. J. 16, 545-554.
[6] Amann, R.I., Krumholz, L., Stahl, D.A. (1990) Fluorescent-oligonucleotide probing of whole cells for determinative, phylogenetic, and environmental studies in microbiology. J. Bacteriol. 172, 762-770.

[7] Beier, S., Bertilsson, S. (2013) Bacterial chitin degradation-mechanisms and ecophysiological strategies. Front. Microbiol. 4, 1-12.

[8] Beier, S., Mohit, V., Ettema, Th.J.G., Östman, Ö., Tranvik, L.J., Bertilsson, S. (2012) Pronounced seasonal dynamics of freshwater chitinase genes and chitin processing. Environ. Microbiol. 14, 2467-2479.

[9] Bennke, Ch.M., Neu, T.R., Fuchs, B.M., Amann, R. (2013) Mapping glycoconjugate-mediated interactions of marine Bacteroidetes with diatoms. Syst. Appl. Microbiol. 36, 417-425.

[10] Bhavanandan, V.P., Katlic, A.W. (1979) The interaction of wheat germ agglutinin with sialoglycoproteins. J. Biol. Chem. 254, 4000-4008.

[11] Biancalana, F., Kopprio, G., Dutto, M.S., Berasategui, A.A., Fricke, A., GarzónCardona, J.E., Peterke, D., Lara, R. (2017) Chitin determination on marine seston in a shallow temperate estuary (Argentina). Braz. J. Oceanogr. 62 (2), 83-91.

[12] Blackwell, J. (1982) The macromolecular organization of cellulose and chitin. In: Brown, R.M., Jr. (Ed.), Cellulose and other natural polymer systems, Plenum Press, New York, London, pp. 403-428.

[13] Boetius, A., Ravenschlag, K., Schubert, C.J., Rickert, D., Widdel, F., Gieseke, A. Amann, R., Jørgensen, B.B., Witte, U., Pfannkuche, O. (2000) A marine microbial consortium apparently mediating anaerobic oxidation of methane. Nature 407 (6804), 623-626.

[14] Bulawa, C.E. (1993) Genetics and molecular biology of chitin synthesis in fungi. Annu. Rev. Microbiol. 47, 505-534.

[15] Cathrine, S.J., Raghukumar, Ch. (2009) Anaerobic denitrification in fungi from the coastal marine sediments off Goa, India. Mycol. Res. 113, 100-109.

[16] Daims, H., Bruhl, A., Amann, R., Schleifer, K.H., Wagner, M. (1999) The domain-specific probe EUB338 is insufficient for the detection of all Bacteria: development and evaluation of a more comprehensive probe set. Syst. Appl. Microbiol. 22, 434-444.

[17] Durkin, C.A., Mock, T., Armbrust, E.V. (2009) Chitin in diatoms and its association with the cell wall. Eukariot. Cell 8, 1038-1050.

[18] Ferreira, T., Rasband, W. 2012 ImageJ user guide IJ 1.46r, pp.170.

[19] Foster, A.J., Bird, R.A., Kelly, S.L., Nishimura, K., Poyner, D., Taylor, S. (2004) FITClectin avidity of Cryptococcus neoformans cell wall and capsular components. Mycologia 96, 1-8.

[20] Giraud-Guille, M.M., Bouligand, Y. (1986) Chitin-protein molecular organization arthropod. In: Muzzarelli, R., Jeuniaux, C., Gooday, G.W. (Eds.), Chitin in nature and technology, Plenum Press, New York, London, pp. 29--35.

[21] Goldstein, I.J., Poretz, R.D. (1986) Isolation and chemical properties of lectins. In: Liener, I.E., Sharon, N., Goldstein, I.J. (Eds.), The lectins: properties, functions and applications in biology and medicine, Academic Press, Orlando, pp. 103-115.

[22] Gooday, G.W. (1990) Physiology of microbial degradation of chitin and chitosan. Biodegradation 1, 177-190.

[23] Gooday, G.W. (1990) The ecology of chitin degradation. Adv. Microb. Ecol. 11 387-430.

[24] Gutiérrez, M.H., Pantoja, S., Tejos, E., Quiñones, R. (2011) The role of fungi in processing marine organic matter in the upwelling ecosystem off Chile. Mar. Biol. 158, 205-219. 
[25] Hara, S., Tanoue, E. (1989) Simultaneous staining with three fluorescent dyes of minute plankters on an agarose gel filter. Deep-Sea Res. 36, 1777-1784.

[26] Jeuniaux, Ch., Voss-Foucart, M.F. (1991) Chitin biomass and production in the marine environment. Biochem. Syst. Ecol. 19, 347-356.

[27] Jobard, M., Rasconi, S., Sime-Ngando, T. (2010) Fluorescence in situ hybridization of uncultured zoosporic fungi: testing with clone-FISH and application to freshwater samples using CARD-FISH. J. Microbiol. Methods 83, 236-243.

[28] Jonhstone, J. (1908) Conditions of life in the sea. In: Shipley, A.E. (Ed.), Cambridge Biological Series, University Press, Cambridge, pp. 30-314.

[29] Kharade, S.S., McBride, M.J. (2014) Flavobacterium johnsoniae chitinase ChiA is required for chitin utilization and is secreted by the type IX secretion system. J. Bacteriol. 196, 961-970.

[30] Lara, R.J., Neogi, S.B., Mohammad, S.I., Mahmud, Z.H., Demoz, B.B., Yamasaki, S., Nair, G.B., Kattner, G. (2011) Vibrio cholerae in waters of the Sundarban mangroves: relationship with biogeochemical parameters and chitin content in seston size fractions. Wetlands Ecol. Manage. 19, 109-119.

[31] Maeda, H., Nakao, I. (1967) Specificity of binding of hexopyranosyl polysaccharides with fluorescent brightener. J. Biochem. 62, 276-278.

[32] Meyberg, M. (1988) Selective staining of fungal hyphae in parasitic and symbiotic plant-fungus associations. Histochemistry 88, 197-199.

[33] Monsigny, M., Sene, C., Obrenovitch, A., Roche, A.C., Delmotte, F., Boschetti, E. (1979) Properties of succinylated wheat-germ agglutinin. Eur. J. Biochem. 98, 39-45.

[34] Montgomery, M.T., Welschmeyer, N.A., Kirchman, D.L. (1990) A simple assay for chitin: application to sediment trap samples from the subarctic Pacific. Mar. Ecol. Prog. Ser. 64, 301-308.

[35] Mulish, M. (1993) Chitin in protistan organisms: distribution, synthesis and deposition. Eur. J. Protistol. 29, 1-18.

[36] Musat, N., Halma, H., Winterhollerb, B., Hoppe, P., Peduzzi, S., Hillion, F., Horreardd, F., Amann, R., Jørgensen, B.B., Kuypers, M.M.M. (2008) A single-cell view on the ecophysiology of anaerobic phototrophic bacteria. Proc. Natl. Acad. Sci. U. S. A. 105, 17861-17866.

[37] Muzzarelli, R.A.A. 1977 Chitin, Pergamon Press, Oxford, New York.

[38] Nicol, S., Hosie, G.W. (1993) Chitin production by krill. Biochem. Syst. Ecol. 21, $181-184$

[39] Pernthaler, A., Pernthaler, J., Amann, R. (2002) Fluorescence in situ hybridization and catalyzed reporter deposition for the identification of marine bacteria. Appl. Environ. Microb. 68, 3094-3101.

[40] Peters, W., Latka, I. (1986) Electron microscopic localization of chitin using colloidal gold labelled with wheat germ agglutinin. Histochemistry 84 (2), $155-160$.

[41] Pinto, A.S., Barreto, C.Ch., Schrank, A., Ulhoa, C.J., Vainstein, M.H. (1997) Purification and characterization of an extracellular chitinase from the entomopathogen Metarhizium anisopliae. Can. J. Microbiol. 43, 322-327.

[42] Pongtippatee, P., Putthawat, W., Dungsuwan, P., Weerachartyanukul, W., Withyachumnarnkul, B. (2012) Hatching envelope formation in the egg of the black tiger shrimp, Penaeus monodon (Decapoda, Penaeidae). Aquac. Res. 44, 1358-1369.

[43] Poulicek, M., Jeuniaux, C. (1991) Chitin biodegradation in marine environments: an experimental approach. Biochem. Syst. Ecol. 19, 385-394.

[44] Pruzzo, C., Vezzulli, L., Colwell, R.R. (2008) Global impact of Vibrio cholerae interactions with chitin. Environ. Microbiol. 10, 1400-1410.

[45] Radek, R., Herth, W. (1999) Ultrastructural investigation of the spore-forming protist, Nephridiophaga blattellae, in the Malpighian tubules of the German cockroach, Blattella germanica. Parasitol. Res. 85, 216-231.

[46] Rasconi, S., Jobard, M., Jouve, L., Sime-Ngando, T. (2009) Use of calcofluor white for detection, identification, and quantification of phytoplanktonic fungal parasites. Appl. Environ. Microbiol. 75, 2545-2553.

[47] Riemann, L., Azam, F. (2002) Widespread N-acetyl-D-glucosamine uptake among pelagic marine bacteria and its ecological implications. Appl. Environ. Microbiol. 68, 5554-5562.

[48] Salazar, O., Asenjo, J.A. (2007) Enzymatic lysis of microbial cells. Biotechnol. Lett. 29, 985-994.

[49] Sekar, R., Pernthaler, A., Pernthaler, J., Warnecke, F., Posch, T., Amann, R. (2003) An improved protocol for quantification of freshwater Actinobacteria by fluorescence in situ hybridization. Appl. Environ. Microbiol. 69, 2928-2935.

[50] Sizemore, R.K., Caldwell, J.J., Kendrick, A. (1990) Alternate gram staining technique using a fluorescent lectin. Appl. Environ. Microbiol. 56, 2245-2247.

[51] Skujins, J., Pukite, A., McLaren, D. (1973) Adsorption and activity of chitinase on kaolinite. Soil Biol. Biochem. 6, 179-182.

[52] Smith, S.N., Armstrong, R.A., Bird, R.A., Chohan, R., Nick, A.H., Poyner, D.A. (2001) Characterization of FITC-conjugated lectin binding to Candida albicans. Mycologia 93, 422-431.

[53] Smucker, R.A. (1991) Chitin primary production. Biochem. Syst. Ecol. 19, 357-369.

[54] Smucker, R.A., Dawson, R. (1986) Products of photosynthesis by marine phytoplankton: chitin in TCA protein precipitate. J. Exp. Mar. Biol. Ecol. 104, 143-152.

[55] Souza, S.P., Almeida, B.C. Colwell, R.R., Rivera, I.N.G. (2011) The importance of chitin in the marine environment. Mar. Biotechnol. 13, 823-830.

[56] Swiontek-Brzezinska, M., Lalke-Porczyk, E., Donderski, W. (2007) Chitinolytic activity of bacteria and fungi isolated from shrimp exoskeletons. Oceanol. Hydrobiol. St. 36, 101-111.

[57] Vimr, E.R., Kalivoda, K.A., Deszo, E.L., Steenbergen, S.M. (2004) Diversity of microbial sialic acid metabolism. Microbiol. Mol. Biol. Rev. 68, 32-53.

[58] Vrba, J., Kofronová-Bobková, J., Pernthaler, J., Símek, K., Macek, M., Psenner, R. (1997) Extracellular, low-affinity b- $N$-acetylglucosaminidases linked to the dynamics of diatoms and crustaceans in freshwater systems of different trophic degree. Int. Rev. Gesamten Hydrobiol. 82, 277-286.

[59] Würzbacher, C., Grossart, H.P. (2012) Improved detection and identification of aquatic fungi and chitin in aquatic environments. Mycologi 104, 1267-1271.

[60] Yoshikoshi, K., Ko, Y. (1988) Structure and function of the peritrophic membranes of copepods. Nippon Suisan Gakk. 54, 1077-1082. 